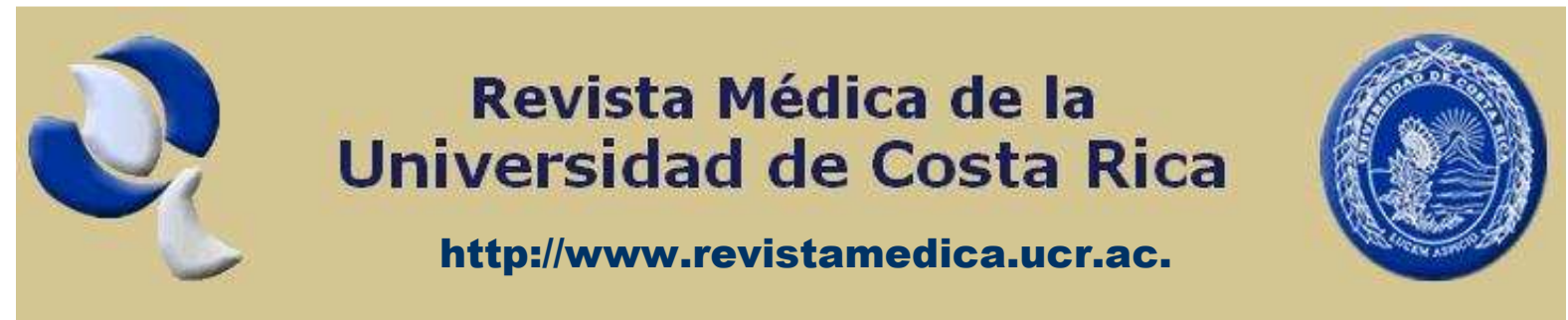

Investigación original

\title{
VALORACIÓN DE LA PRESCRIPCIÓN DE ANTIBIÓTICOS EN ADULTOS DIAGNOSTICADOS CON FARINGOAMIGDALITIS, PERÍODO 2004-2007
}

\author{
Chaverri Calvo, Carlo ${ }^{1}$; Gätjens Torres, Karol $^{1}$; Zavaleta Monestel, Esteban ${ }^{2}$ y \\ Chaverri Fernández, José Miguel ${ }^{3}$. \\ ${ }^{1}$ Estudiantes Internos de Farmacia. Universidad de Costa Rica, ${ }^{2}$ Coordinador Farmacéutico. Farmacia \\ Hospital Clínica Bíblica, Costa Rica. ${ }^{3}$ Farmacéutico. Centro Nacional de Información de Medicamentos. \\ Instituto de Investigaciones Farmacéuticas, INIFAR, Facultad de Farmacia. Universidad de Costa Rica.
}

Resumen: La faringitis es uno de los principales padecimientos valorados por los médicos familiares. Los agentes etiológicos más comunes para este padecimiento son los virus y en una proporción más baja de bacterias. Para el tratamiento de este tipo de infecciones a menudo se utilizan antibióticos de manera inadecuada e innecesaria, ya que, en la mayoría de los casos, estos confieren poco o ningún beneficio, o se procede a instaurar tratamiento antibiótico con medicamentos que no son de primera línea para el control de las mismas. La mayor parte de los médicos que laboran en el servicio de urgencias del Hospital Clínica Bíblica actualmente prefieren utilizar métodos clínicos y sintomatológicos para su diagnóstico, prescribiendo, posteriormente, antibióticos en un porcentaje mucho más elevado con respecto a lo observado y sugerido por la literatura, seleccionando, en una gran cantidad de casos, tratamientos o combinaciones no respaldadas con evidencia clínica y epidemiológica adecuada. Los prescriptores de dicho centro señalan como sus tratamientos de elección a las penicilinas orales para el manejo de la faringoamigdalitis bacteriana, los datos recopilados en esta investigación muestran una tendencia diferente en el proceso de prescripción.

Palabras clave: Antibióticoterapia, faringoamigdalitis, antibióticos, vías respiratorias

Recibido: Diciembre 2007. Aceptado: Febrero 2008. Publicado: Marzo 2008.

Revista electrónica publicada por el Departamento de Farmacología de la Escuela de Medicina de la Universidad de Costa Rica, 2060 San José, Costa Rica. ( ${ }^{\circledR}$ All rights

reserved. 
Abstract: Pharyngitis is one of the most common medical diseases attended by family doctors in the United States and Latin-American. Typical transmission is caused by virus and bacteria. Antibiotics are usually not used in a correct way in order to treat this kind of infections, even though they offer poor or non benefit to control this pathology. Most part of the doctors that work in the Emergency Room of Hospital Clínica Bíblica prefer to use sintomatological methods and clinical assessment to treat this disease, they prescribe antibiotics in a higher percentage than the observed in literature, although they say to prefer to use oral penicillin as their election choice to treat bacterial pharyngitis, the data we found shows a variety of drugs that they use to control it, in some cases not in the best way.

Keywords: Antibiotic drug therapy, pharyngoamydalitis, antibiotics, upper airways

\section{Introducción}

La faringitis aguda es un tipo de inflamación faríngea causada generalmente por una infección. Independientemente de la etiología, ya sea viral o bacteriana, el principal síntoma de la faringitis aguda es el dolor, acompañado o no de disfagia. La inspección puede revelar exudados, eritema, congestión de la mucosa con hipertrofia del tejido linfoide, especialmente de las amígdalas palatinas [5]. Ninguno de los síntomas (incluyendo la inflamación de garganta o faringitis) y ninguno de los signos (incluyendo el exudado faríngeo o las esporádicas petequias en el paladar) son específicos de una infección bacteriana [10, 12]; cualquiera de los rasgos clínicos, o todos ellos, pueden aparecer en una infección vírica, en particular en las provocadas por adenovirus y mononucleosis infecciosa $[10,12]$. El único signo estadísticamente asociado a serología confirmada de enfermedad estreptocócica bacteriana es la adenitis cervical. La transmisión típica es debida, principalmente, al contacto con secreciones nasales y en menor cantidad a la vía oral [19]. El estreptococo $\beta$-hemolítico del grupo $A$
(Streptococcus pyogenes) es el causante de aproximadamente un 15-30 $\%$ de los casos de faringitis en niños y de un $5-10 \%$ de casos en adultos [2]. La faringitis viral es la causa más común de molestias en la garganta, se han reportado síntomas asociados como coriza, conjuntivitis, malestar o fatiga y fiebre de baja intensidad [3]. La identificación del ente causal bacteriano es importante, especialmente si se trata del estreptococo $\beta$ - hemolítico del grupo $A$, ya que con esto se consigue la prevención de futuras complicaciones como lo son la fiebre reumática, la glomerulonefritis aguda y complicaciones supurativas como abscesos periamigdalinos, linfadenitis cervical y celulitis [3, 15]. El desarrollo de una óptima diferenciación entre los distintos causantes de esta patología requiere enfocar la valoración inicial en puntos como la historia del paciente, el examen físico y una apropiada prueba de laboratorio [18]. El cultivo faríngeo es el método estándar para documentar la presencia de Streptococcus pyogenes, los falsos positivos son probables en pacientes con una pequeña cantidad de organismos en la faringe [2].

Revista electrónica publicada por el Departamento de Farmacología de la Escuela de Medicina de la Universidad de Costa Rica, 2060 San José, Costa Rica. ® All rights 
La infección faríngea primaria producida por estreptococo $\beta$ - hemolítico del grupo A sintomatológica ocurre en aproximadamente el $20 \%$ de los enfermos con infecciones; el resto permanece asintomático, presenta fiebre 0 bien dolor de garganta moderado que se asemeja a una faringitis vírica [1].

Los antibióticos se utilizan a menudo inadecuadamente para tratar infecciones del tracto respiratorio superior, esto a pesar de que en la mayoría de los casos los antibióticos confieren poco o ningún beneficio [15, 18]; surge entonces la preocupación por el abuso de los mismos, lo cual conduce a incrementar los costos de tratamiento innecesariamente, a que potencialmente se generen efectos nocivos para el individuo que recibe esta terapia y a que el uso excesivo de antibióticos pueda conducir al desarrollo resistencia bacteriana [12]. Para ayudar a los médicos a mejorar el empleo de la terapéutica antibiótica a nivel del tracto respiratorio superior, el Centro para el Control y Prevención de Enfermedades (CDC) en los Estados Unidos creó pautas para el uso apropiado de antibióticos en el adulto. Las mismas, publicadas en el 2001, fueron adoptadas por la Academia Americana de Médicos de Cabecera, la Universidad Americana

\section{Materiales y Métodos}

El presente trabajo se describe como un estudio retrospectivo observacional diseñado con el objetivo de valorar la prescripción de antibióticos en pacientes adultos diagnosticados con faringoamigdalitis aguda en el servicio de Urgencias del Hospital Clínica Bíblica en Costa Rica durante el período 20042007. La población total pacientes, de la Sociedad Médico-Americana de Medicina Interna, y la Sociedad Americana de Enfermedades Infecciosas [12]. Se establece entonces que para el manejo de una faringitis aguda el uso antibiótico debe limitarse a los pacientes que tengan una mayor probabilidad de presentar al estreptococo $\beta$ hemolítico como agente causal de la misma, si es así, el antibiótico de elección es la penicilina $\mathrm{V}$ o penicilina $\mathrm{G}$ benzatínica $[12,20]$ o en pacientes alérgicos a esta se prefiere eritromicina [12], en el caso de la Caja Costarricense del Seguro Social en Costa Rica, la utilización de este fármaco tiende a ir en franco desuso, donde las recomendaciones o elección de los antibióticos se basa más en los criterios clínicos y en los datos epidemiológicos de cada centro de salud. Como tratamientos alternativos están la amoxicilina, cefalosporinas orales, y para pacientes alérgicos a penicilina, se eligen los macrólidos y clindamicina. La duración habitual del tratamiento es de diez días [20].

La Azitromicina no se recomienda como terapia de primera línea para faringitis por Streptococcus del grupo $A$; sin embargo, muchos médicos encuentran atractivo el régimen de una dosis de azitromicina al día por cinco días [11].

diagnosticada con faringoamigdalitis aguda en el Servicio de Urgencias del Hospital fue de 160. La población total utilizada fue seleccionada con base en los siguientes criterios de inclusión: edades entre 18-65 años, ambos géneros y que hayan sido clasificados clínicamente y de manera empírica por los médicos tratantes durante la

$\overline{\text { Revista electrónica publicada por el Departamento de Farmacología de la Escuela de }}$ Medicina de la Universidad de Costa Rica, 2060 San José, Costa Rica. ${ }^{\circledR}$ All rights reserved. 
consulta según la ICD-10 (Clasificación estadística internacional de enfermedades y problemas de salud relacionados) de la Organización Mundial de la Salud (Ver Tabla No 1).

Se excluyeron los pacientes que se clasificaron según la ICD-10 y que cumplían con los siguientes diagnósticos: A38 (fiebre escarlata), B08.5 (enterovirus vesicular), B00.2 (Herpes viral), B27 (mononucleosis infecciosa), J09-J10.1 (Virus de la influenza identificado), J11.1 (Virus de la influenza no identificado), Abscesos J36 (periamigdalino), J39.1 (faríngeo), J39.0 (retrofaríngeo), J06.0 (laringofaringitis aguda), J31.2 (faringitis crónica) [17].

Se procedió a recopilar el número de casos del Servicio de Urgencias del Hospital diagnosticados con faringitis aguda, esto mediante un listado de pacientes obtenido a través del sistema de cómputo.

Tabla No 1

Clasificación estadística internacional de enfermedades y problemas de salud relacionados de la Organización Mundial de la Salud [17]

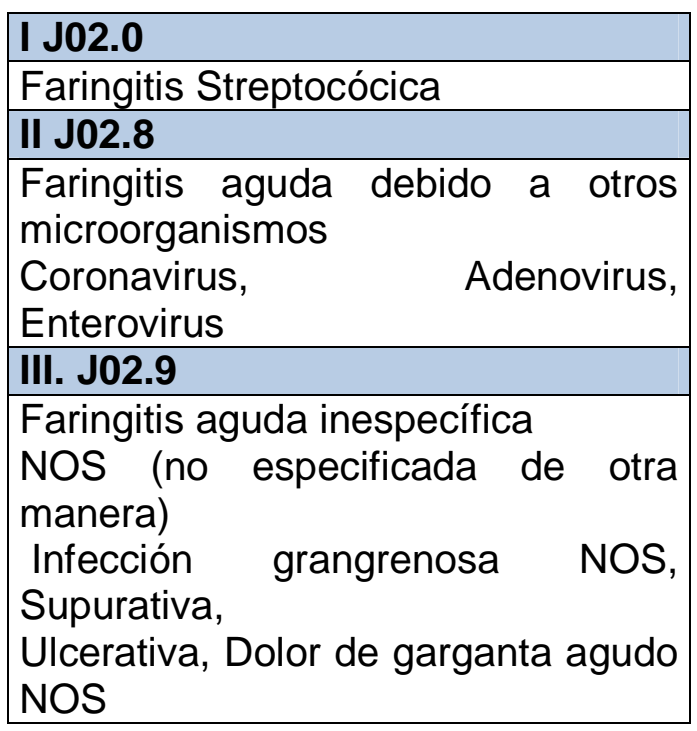

Se procedió a seleccionar los casos en los que la fecha de diagnóstico se encontraba entre el $1^{\circ}$ de enero de 2004 y el 31 de diciembre de 2006 y que además cumplieran con los criterios de inclusión. Los datos fueron proporcionados por el Hospital con la autorización de la Dirección Médica de la institución, en ausencia aún de un Comité Ético Científico. A los datos se les verificó el diagnóstico de faringitis aguda y la terapia antibiótica empleada para el manejo de esta patología, junto con características importantes de cada paciente y el abordaje terapéutico utilizado como complemento al tratamiento antibiótico. Los datos obtenidos se tabularon y graficaron mediante la utilización de herramientas informáticas como excel y el programa de estadística SPSS (Stadistical Program for the Social Sciences) $V^{15.0}$, para una mejor comprensión y análisis de los mismos. Se establecieron comparaciones entre los datos obtenidos en el estudio y los datos teóricos recopilados en la literatura, tomando como puntos de referencia los lineamientos indicados en la Guía Sanford de Tratamiento Antimicrobiano 2006 y los Lineamientos para el Uso de Antibióticos en Infecciones Agudas del Tracto Superior Respiratorio publicadas en el año 2006 en la revista American Family Physician [11, 20]. La existencia de condiciones externas que ejerzan algún tipo de presión en el médico para prescribir fue valorada mediante entrevistas realizadas a un grupo de cinco médicos que laboran usualmente en esta sección del Hospital. En promedio, cinco, es el número de profesionales en medicina que labora en el área de urgencias del hospital y que se encargan de atender este tipo de casos.

$\overline{\text { Revista electrónica publicada por el Departamento de Farmacología de la Escuela de }}$ Medicina de la Universidad de Costa Rica, 2060 San José, Costa Rica. ${ }^{\circledR}$ All rights 


\section{Resultados}

De acuerdo a los criterios de inclusión establecidos al inicio de la investigación se obtuvo una población de 160 pacientes o casos atendidos. A esta se le determinó su distribución en cuanto a edad y sexo. Se estudiaron otras variables que indican el manejo recibido por el paciente diagnosticado con faringoamigdalitis aguda en el Servicio de Urgencias del Hospital. La población femenina representó un $52.5 \%$, mientras que la población masculina fue de un $47.5 \%$. El promedio de edad de los pacientes fue de 33 años, siendo 18 años la edad mínima y 58 años la edad máxima. De acuerdo a los códigos de clasificación de diagnósticos de faringitis aguda que dicta la Organización Mundial de la Salud, la población se distribuyó según lo muestra la Tabla No 2, la clasificación fue empírica según el criterio clínico del tratante, y esta no se ajusta a criterios firmes. Es importante mencionar que en esta clasificación, la categoría correspondiente a Faringitis Aguda inespecífica, no indica si el origen de esta patología es viral o bacteriano, por lo que se dificulta establecer cual sería el mejor abordaje terapéutico para este tipo de faringitis. La prescripción de antibioticoterapia en los pacientes en estudio se refleja en la tabla No 3. Se puede apreciar que el $75.6 \%$ de la población recibió tratamiento antibiótico para abordar la faringoamigdalitis. En lo que respecta a la distribución de los distintos antibióticos utilizados para el tratamiento de la faringitis podemos destacar que las penicilinas orales son los antibióticos que más se prescribieron con un $20.6 \%$. A su vez resalta la utilización de combinaciones de cefalosporinas de diferente generación, o cefalosporinas junto a macrólidos o quinolonas.
También se registraron asociaciones de penicilina benzatínica junto a macrólidos o cetólidos. En un paciente se utilizó una combinación de tres antibióticos que incluía una penicilina oral, penicilina $G$ benzatínica y una cefalosporina de tercera generación (Tabla No 4).

En un $98.8 \%$ de los casos no se les realizó una prueba de laboratorio que confirmara la presencia bacteriana. El mayor porcentaje de las faringitis estreptocócicas fueron diagnosticadas por médicos internistas (51.8\%), mientras que los médicos generales diagnosticaron mayor cantidad de faringitis aguda inespecífica (49.5\%). La clase de antibiótico prescrito de acuerdo al tipo de médico especialista que llevó a cabo la consulta, muestra que la mayor cantidad de penicilina $G$ benzatínica fue prescrita por médicos internistas, mientras que los médicos generales muestran preferencia por las penicilinas orales. En un $93.1 \%$ de casos que reportan tratamiento de sostén o de control sintomatológico adicionado o no al tratamiento antibiótico, fue prescrito en mayor cantidad por médicos generales. El número de pacientes que solicitaron una revaloración se presentan en la tabla No 5 .

Revista electrónica publicada por el Departamento de Farmacología de la Escuela de Medicina de la Universidad de Costa Rica, 2060 San José, Costa Rica. ${ }^{\circledR}$ All rights reserved. 
Tabla No 2: Diagnóstico de faringitis aguda según clasificación de la OMS

\begin{tabular}{|l|c|c|}
\hline \multicolumn{1}{|c|}{ Tipos de Faringitis } & * No de Casos & $\%$ \\
a. Faringitis Estreptocócica & 56 & 35.0 \\
b. Faringitis Aguda no especifica & 95 & 59.4 \\
c. Faringitis Aguda debido a & 9 & 5.6 \\
otros microorganismos: & & \\
Coronavirus, Adenovirus, & & \\
Enterovirus & 160 & 100.0 \\
\hline \multicolumn{1}{|c|}{ Total } & & \\
\hline
\end{tabular}

* Recordemos que la clasificación fue empírica según el criterio clínico del tratante, y esta no se ajusta a criterios firmes.

Tabla No 3: Índice de prescripción de tratamiento antibiótico

\begin{tabular}{|c|c|c|}
\hline $\begin{array}{c}\text { Prescripción } \\
\text { antibiótica }\end{array}$ & No de casos & Porcentaje \\
No & 39 & 24.4 \\
Si & 121 & 75.6 \\
Total & 160 & 100.0 \\
\hline
\end{tabular}

$\overline{\text { Revista electrónica publicada por el Departamento de Farmacología de la Escuela de }}$ Medicina de la Universidad de Costa Rica, 2060 San José, Costa Rica. ${ }^{\circledR}$ All rights reserved. 
Es importante destacar que el mayor porcentaje de revaloración se presentó con los pacientes que se les utilizo como terapia erradicativa cefalosporinas de tercera generación, en este caso particular ceftriaxona. Se realizó un sondeo en el cual fueron entrevistados cinco médicos, la mayor parte de ellos con edades promedio de 35 años y un tiempo promedio de laborar en este servicio de 4 años. Al preguntar acerca de la existencia de algún tipo de predilección para la escogencia del tratamiento antibiótico para la faringoamigdalitis estreptocócica, el 100\% dijo si tener preferencias. Al indagar el tipo de antibiótico de elección, cuatro de ellos manifestaron inclinarse hacia la utilización de penicilinas orales y uno prefirió la penicilina benzatínica. Al consultar si se presenta presión por parte del paciente, la enfermera, laboratorio o visitadores médicos, para la prescripción de un tratamiento antibiótico en especial, el 100\% respondió que no se recibe ningún tipo de presión externa en este proceso.

\section{Discusión}

En la presente investigación fueron estudiados 160 pacientes con edades entre 18-65 años con el fin de analizar una población con características similares. La incidencia de faringitis estreptocócica que se reporta en la literatura para pacientes adultos es de un $5-10 \%$, por lo que la mayoría de las faringitis son de origen viral [2], sin embargo en el servicio de urgencias de este centro hospitalario se muestra un comportamiento diferente; como se refleja en los resultados, donde un $35 \%$ de los de los casos corresponde a faringitis estreptocócica, un 59.4\% a faringitis aguda inespecífica y solo un $5.6 \%$ a faringitis de origen viral o debida a otros microorganismos, la clasificación acá establecida se dio por parte de la clínica encontrada por el facultativo en los pacientes y no conlleva ninguna valoración en firme de la misma.

Es importante definir que la faringitis aguda inespecífica incluye los siguientes tipos: infección grangrenosa NOS (no sea especificada de otra manera), supurativa y ulcerativa; esta clasificación no

establece si este tipo de faringitis es de origen viral 0 bacteriana por lo que dificulta esclarecer la utilización de tratamiento antibiótico para el abordaje de esta patología, así como la comparación de estadísticas epidemiológicas referentes a la incidencia de faringitis bacteriana. A su vez, la faringitis debido a otros microorganismos se define como la 
Tabla No 4: Tipo de antibiótico prescrito

\begin{tabular}{|c|c|c|}
\hline Antibiótico & Frecuencia & Porcentaje \\
\hline Penicilina Benzatínica & 11 & 6.9 \\
\hline Penicilinas Orales & 33 & 20.6 \\
\hline Cefalosporinas $1^{\circ}$ generación & 3 & 1.9 \\
\hline Cefalosporinas $2^{\text {a }}$ generación & 1 & 0.6 \\
\hline Cefalosporinas $3^{\circ}$ generación & 13 & 8.1 \\
\hline Macrólidos & 19 & 11.9 \\
\hline Cetólidos & 7 & 4.4 \\
\hline Quinolonas & 10 & 6.3 \\
\hline Cefalosporina + Macrólidos & 2 & 1.3 \\
\hline Cefalosporinas + Quinolonas & 5 & 3.1 \\
\hline $\begin{array}{l}\text { Cefalosporina } 1^{\circ}+\text { Cefalosporina } \\
3^{\circ}\end{array}$ & 1 & 0.6 \\
\hline Sulfonamidas & 1 & 0.6 \\
\hline Lincosamidas & 1 & 0.6 \\
\hline $\begin{array}{l}\text { Penicilina Benzatínica }+ \\
\text { Penicilina oral }\end{array}$ & 2 & 1.3 \\
\hline $\begin{array}{l}\text { Penicilina Benzatínica }+ \\
\text { Cefalosporina } \mathbf{1}^{\mathbf{0}}\end{array}$ & 2 & 1.3 \\
\hline $\begin{array}{l}\text { Penicilina Benzatínica }+ \\
\text { Cefalosporina } 3^{\mathbf{o}}\end{array}$ & 1 & 0.6 \\
\hline $\begin{array}{l}\text { Penicilina } \text { Benzatínica }+ \\
\text { Penicilina Oral }+ \text { Cefalosporina } \\
\text { 3 }^{\mathbf{0}}\end{array}$ & 1 & 0.6 \\
\hline $\begin{array}{l}\text { Penicilina } \quad \text { Benzatínica } \quad+ \\
\text { Macrólido }\end{array}$ & 3 & 1.9 \\
\hline Penicilina Benzatínica + Cetólido & 5 & 3.1 \\
\hline Sin tratamiento & 39 & 24.4 \\
\hline Total & 160 & 100.0 \\
\hline
\end{tabular}

$\overline{\text { Revista electrónica publicada por el Departamento de Farmacología de la Escuela de }}$ Medicina de la Universidad de Costa Rica, 2060 San José, Costa Rica. ® All rights reserved. 
infección producida por coronavirus, adenovirus y enterovirus según lo establecido por la OMS. Como se puede apreciar el índice de faringitis de origen estreptocócica es alto, en comparación con lo indicado en la literatura, sin embargo es importante destacar que el método estándar para el diagnóstico de las misma es el cultivo faríngeo [2], y según muestra en los resultados sólo a un $1.3 \%$ de los pacientes se le realizó una prueba de laboratorio, para comprobar la presencia de la bacteria u otro microorganismo. Esto refleja que, en la mayoría de los casos los médicos determinan si esta patología es de origen bacteriano o no según los signos y síntomas que presente el paciente. Condiciones como garganta adolorida, fiebre, dolor de cabeza, náusea, vómito, dolor abdominal, eritema faringoamigdalino, exudados, 0 presencia de nódulos linfocervicales anteriores agrandados, indican la presencia de un estreptococo $\beta$ hemolítico del grupo $A$, no obstante se reafirma que el diagnóstico se debe confirmar con el cultivo de faríngeo o la prueba rápida del antígeno [1, 20]. Lo anterior se recalca en los Lineamientos Establecidos para el Uso de Antibióticos en Infecciones Agudas del Tracto Superior Respiratorio publicadas en el año 2006 [20], donde se indica que los médicos pueden guiarse por la presencia de signos como fiebre, ausencia de tos, adenopatía cervical, exudado amigdalino, y la edad del paciente, para así mediante un sistema de puntaje establecido, determinar si la faringitis es estreptocócica o no [20].

Se establece que para el manejo de una faringitis aguda el uso antibiótico debe limitarse para los pacientes que tengan una mayor probabilidad de presentar al estreptococo $\beta$-hemolítico como agente causal de la misma [12]. La prueba rápida de antígeno es una alternativa a utilizar para confirmar la presencia de esta bacteria, su especificidad es de un $95 \%$, su sensibilidad se encuentra entre $70 \%$ y $90 \%$ y la duración de la prueba es de aproximadamente 2 horas. El índice de prescripción de tratamiento antibiótico fue de un $75.6 \%$, el cual es mucho mayor que el porcentaje de diagnóstico de faringitis estreptocócica correspondiente a $35 \%$, sin embargo y debido a que la clasificación de la OMS no es clara al definir si la faringitis aguda no específica es de origen viral o bacteriana y la clasificación es empírica, no se puede establecer una relación entre el índice de prescripción de antibióticos y el total de faringitis de origen bacteriano que se presenta en este servicio. La correcta prescripción de tratamiento antibiótico según la Guía Sanford de Tratamiento Antimicrobiano 2006, indica, como tratamiento de primera elección para una faringoamigdalitis con eritema exudativo - difuso cuya etiología sea el estreptococo $\beta$ hemolítico del grupo $A$, la penicilina $\mathrm{V}$ o la Penicilina Benzatínica si el cumplimiento oral no fuera posible; como una segunda opción se citan las penicilinas orales (amoxicilina, ampicilina) o azitromicina en caso de alergia a penicilina [16]. Como se puede observar en los resultados las penicilinas orales son los antibióticos con mayor porcentaje de prescripción, seguido por macrólidos y en tercer lugar por la Penicilina Benzatínica. Es importante destacar la utilización por parte de los prescriptores de esquemas de tratamiento que incluyen la aplicación de cefalosporinas de tercera generación de forma de dosis única, o en

$\overline{\text { Revista electrónica publicada por el Departamento de Farmacología de la Escuela de }}$ Medicina de la Universidad de Costa Rica, 2060 San José, Costa Rica. ${ }^{\circledR}$ All rights reserved. 
Tabla No 5: Índice de pacientes que solicitaron revaloración

\begin{tabular}{|c|c|c|}
\hline \multicolumn{1}{|c|}{ Índice } & No de casos & Porcentaje \\
No & 153 & 95.6 \\
Si & 7 & 4.4 \\
Total & 160 & 100.0 \\
\hline
\end{tabular}

combinación con antibiótico oral como penicilinas, cefalosporinas, o macrólidos. Igualmente se presentan mezclas de cefalosporinas de tercera generación con Penicilina Benzatínica. Esta clase de combinaciones no se reportan como esquemas de tratamiento para el manejo de la faringitis aguda estreptocócica en la literatura consultada, ni tampoco se respalda la utilización de cefalosporinas de tercera generación en dosis única para el tratamiento de esta patología en adultos. El empleo de antibióticos macrólidos se ubica en segundo lugar; la tendencia a utilizar esta clase de antibióticos es muy alta, esto probablemente se deba a que los esquemas de tratamiento son más cortos en comparación con las penicilinas orales, sin embargo es importante destacar que hasta un 35\% de microorganismos aislados son resistentes a eritromicina, azitromicina, claritromicina y clindamicina [11], por lo que su empleo se debe reservar para los casos en que los pacientes sean alérgicos a penicilinas, para disminuir la posibilidad de resistencia. Se puede apreciar que un porcentaje significativo de la prescripción de antibióticos lo constituyen la telitromicina 0 la lincosamina, los cuales no se consideran opciones a emplear para el tratamiento de esta patología. En el caso específico de la telitromicina la FDA solamente aprueba su utilización para el manejo de neumonía bacteriana, esto debido a los problemas a nivel hepático como la elevación de transaminasas y hepatitis que puede provocar este medicamento [8]. Por su lado las quinolonas se utilizan en un porcentaje muy similar a la Penicilina Benzatínica, recordemos que la Guía Sanford de Tratamiento Antimicrobiano 2006 establece que las quinolonas se emplean solamente cuando el paciente es alérgico a penicilinas y además se comprueba que la bacteria es resistente a macrólidos [11]. Se indicaron solamente dos pruebas de laboratorio para la confirmación y presencia de bacterias en la zona, estas fueron solicitadas por medicina general y un médico sin especialidad definida en el expediente del paciente. Por lo anterior se recalca que a la mayor parte de los pacientes que recibieron tratamiento antibiótico no se les realizó una prueba que confirmara la presencia del patógeno, que justifique la utilización de quinolonas o combinaciones antibióticas no aprobadas como efectivas por los lineamientos internacionales establecidos en la Guía Sanford de

Revista electrónica publicada por el Departamento de Farmacología de la Escuela de Medicina de la Universidad de Costa Rica, 2060 San José, Costa Rica. ® All rights reserved. 
Tratamiento Antimicrobiano 2006 [11]. Solo a 11 pacientes no les fue prescrito tratamiento de control sintomatológico. Los principales tratamientos de sostén utilizados consistieron principalmente en medicamentos analgésicos, antiinflamatorios y en algunos casos descongestionantes y mucolíticos.

Uno de los principales objetivos de esta investigación fue determinar si existió una tendencia en la prescripción de antibióticos para el manejo de la faringitis aguda bacteriana, los datos recopilados indicaron que los cinco médicos consultados dijeron si preferir un tipo de antibiótico, cuatro de ellos se inclinaron por las penicilinas orales (amoxicilina, ampicilina) para el manejo de esta patología. Este punto no concuerda con los datos obtenidos, ya que aunque si existe predilección por las penicilinas orales, se muestra una gran

\section{Conclusiones}

No se pudo determinar con exactitud el porcentaje de Faringoamigdalitis de origen bacteriano, ya que la clasificación de la Organización Mundial de la Salud no establece si la faringitis aguda no específica es de origen viral 0 bacteriano; por esta razón sería recomendable utilizar criterios de clasificación más estrictos en los cuales se delimite el origen de esta patología. Al no tener en la mayoría de las ocasiones una prueba de laboratorio que confirme el diagnóstico de una faringoamigdalitis según patógeno, se concluye que el médico realiza el diagnóstico basado en los signos y síntomas que presenta el paciente solamente, y por ende podría incurrir en errores a la hora de clasificar la patología en el expediente. La prueba rápida de antígeno se realiza en esta diversidad de antibióticos prescritos para esta patología.

Otro punto importante a evaluar es la presión externa que recibe el médico durante el proceso de prescripción del tratamiento antibiótico. La literatura reporta que si el médico percibe que el paciente espera recibir un antibiótico como parte de su terapia, la probabilidad de que le sea prescrito por parte del médico es 10 veces mayor [18]. Por esta razón se consultó la existencia de algún tipo de presión por parte del paciente, la enfermera, laboratorios farmacéuticos o visitares médicos, esto para llevar a cabo la prescripción de un tratamiento antibiótico. Ante esta interrogante todos los médicos consultados respondieron que no existen factores coaccionantes durante el proceso, lo cual no concuerda con lo reportado en la literatura.

institución y tiene una duración de dos horas, por lo que es aconsejable incentivar al personal médico para que la utilice durante el proceso de diagnóstico. Es recomendable instaurar en el hospital un modelo a seguir para realizar el diagnóstico de una faringoamigdalitis estreptocócica tomando como base los signos y síntomas del paciente. Los lineamientos establecidos para el Uso de Antibióticos en Infecciones Agudas del Tracto Superior Respiratorio publicadas en el año 2006 se presentan como una buena opción; en estos se indica que los médicos pueden guiarse por la presencia de signos como fiebre, ausencia de tos, adenopatía cervical, exudado amigdalino, y la edad del paciente, para mediante un sistema de puntaje previamente establecido,

$\overline{\text { Revista electrónica publicada por el Departamento de Farmacología de la Escuela de }}$ Medicina de la Universidad de Costa Rica, 2060 San José, Costa Rica. ${ }^{\circledR}$ All rights reserved. 
determinar si la faringitis es estreptocócica o no [20]. Se presentó un porcentaje de prescripción antibiótica elevado $(75.6 \%)$, esto a pesar de que solamente al $1.8 \%$ de los pacientes se les realizó una prueba de laboratorio para comprobar si la patología era de origen bacteriano, aspecto que contradice lo establecido en la literatura donde se indica que para el manejo de una faringitis aguda el uso antibiótico debe limitarse para los pacientes que tengan una mayor probabilidad de

\section{Bibliografía}

1. Berkow R, Fletcher A. Editores. Manual Merck de Diagnóstico y Terapéutica. 9a ed. España: Mosby/ Doyma Libros; 199.

2. Bisno A. Acute Pharyngitis. $\mathrm{N}$ Engl J Med. 2001; 344 (3): 205-211.

3. Block S. Short-Course Antimicrobial Therapy of Streptococcal Pharyngitis. Clin Pediatr. 2003; 42: 663-671.

4. Braun S. Estudio Microbiológico del tracto Respiratorio Superior. Rev Chil Infect. 2003; 20(3): 193-198.

5. Braunwald E, Fauci A, Dennis K, Longo D, Jameson L. Editores Harrison

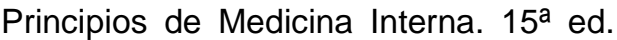
España. McGraw-Hill; 2002.

6. Brunton LL, Lazo JS, Parker KL. Editores. Goodman \& Gilman's the Pharmacological Basis of Terapeutics.11th ed. New York: McGraw-Hill; 2006.

7. Casey, J., Pichichero, M. Meta-analysis of Cephalosporin Versus Penicillin Treatment of Group A Streptococcal Tonsillopharyngitis in Children. Pediatrics. 2004; 113 (4): 866-882. presentar al estreptococo $\beta$-hemolítico como agente causal de la misma y debe ser confirmado con un cultivo faríngeo [12]. No se encontró evidencia en la literatura que respalde la utilización de antibióticos como las cefalosporinas de tercera generación, y combinaciones de estos con antibióticos orales para el tratamiento de esta patología. De la misma forma no se encontró evidencia que justifique el uso de combinaciones de penicilina benzatínica con antibióticos orales.
8. FDA Public Health Advisory Ketek (telithromycin) Tablets. Página official de la U.S. Food and Drug Administration (FDA).

http://www.fda.gov/cder/drug/advisory/tel ithromycin. Accesada el 19 de abril de 2007.

9. Fica A. Tratamientos Antimicrobianos Abreviados en Pacientes Adultos. Rev Chil Infect. 2004; 21(3): 1999-2007.

10. Flores J. Farmacología Humana. $3^{\underline{a}}$ ed. Barcelona: Masson, S.A.; 1998.

11. Gilbert D, Moellering R, Eliopoulos R, Sande M. Editores. Guía Sanford de Tratamiento Antimicrobiano. 39 a ed. Estados Unidos de América: Antimicrobial Therapy, Inc; 2006.

12. Gill, J., Fleischut, $P$ et al. Use of Antibiotics for Adult Upper Respiratory Infections in Outpatient Settings. Fam Med. 2006; 38(5): 349-354.

13. Martin, J., Green, M et al. ErytromycinResistant Group A Streptococci in Schoolchildren in Pittsburgh. Engl $\mathrm{J}$ Med. 2002; 346(16): 1200-1206.

14. Mc Isaac, W., Kellner, J et al. Empirical Validation of Guidelines for the

$\overline{\text { Revista electrónica publicada por el Departamento de Farmacología de la Escuela de }}$ Medicina de la Universidad de Costa Rica, 2060 San José, Costa Rica. ® All rights reserved. 
Management of Pharyngitis in Children and Adults. JAMA. 2004; 291(13) 15871595.

15. Muñoz, S., Córdova, $M$ et al. Faringitis Aguda, ¿Estreptocócica? Empleo del Estudio Etiológico y de Antimicrobianos en dos centros pediátricos universitarios. Rev Chil Infect. 2005;22 (2): 147-153.

16. Reinert R. Clinical Efficacy of Ketolides in the treatment of Respiratory Tract Infections. JAC. 2004; 53(6): 918-927.

17. Rimon ,W., Hamza ,H et al. Evaluation of WHO Clinical Decision Rule for Streptococcal Pharyngitis. Arch Dis Child. 2005; 90: 1666-1070.

18. Van Driel, M., De Sutter, A., Deveugele, $\mathrm{M}$ et al. Are Sore Throat Patients Who
Hope for Antibiotics Actually Asking for Pain Relief? Ann Fam Med.2006; 6(4): 494-499.

19. Vincent, M., Celestin, $\mathrm{N}$ et al. Pharyngitis. Am Fam Physician. 2004; 69(6): 1465-147.

20. Wong, D., Blumberg, D et al. Guidelines for Use of Antibiotics in Acute Upper Respiratory Tract Infections. Am Fam Physician. 2006; 74(6): 956-966.

21. ZmaxTM (azithromycin extended release) for oral suspension. Página oficial de ZmaxTM (azithromycin extended release) for oral suspension. http://www.pfizer.com/pfizer/download/u spi_zmax.pdf. Accesada el 21 de abril de 2007.

\section{Correspondencia:}

\section{José Miguel Chaverri Fernández.}

Centro Nacional de Información de Medicamentos. Facultad de Farmacia. Universidad de Costa Rica. Apartado Postal 2060 San José, Costa Rica. Tel. 207-3476 Fax 207-5700.

Correo electrónico: imchaverri@cimed.ucr.ac.cr ó imchaverri@farmacia.ucr.ac.cr

$\overline{\text { Revista electrónica publicada por el Departamento de Farmacología de la Escuela de }}$ Medicina de la Universidad de Costa Rica, 2060 San José, Costa Rica. (®) All rights reserved. 